\title{
Mechanical Properties of Composites Reinforced with Textile
}

\author{
OANA DODUN ${ }^{1}$, LAURENTIU SLATINEANU ${ }^{1}$, GHEORGHE NAGIT ${ }^{1 *}$, MARIAN MARES ${ }^{2}$, \\ ADELINA HRITUC ${ }^{1}$, MARGARETA COTEATA ${ }^{1}$, IRINA BESLIU BANCESCU ${ }^{3}$ \\ ${ }^{1}$ Gheorghe Asachi Technical University of Iasi, Department of Machine Manufacturing Technology, 59A D. Mangeron Blvd., 700050, \\ Iasi, Romania \\ ${ }^{2}$ Gheorghe Asachi Technical University of Iaşi, Department of Mechanical Engineering, Mechatronics and Robotics, 59A D. Mangeron \\ Blvd., 700050, Iasi, Romania \\ ${ }^{3}$ Stefan cel Mare University of Suceava, Department of Mechanics and Technologies, 12 Universitatii Str., 720229, Suceava, Romania
}

\begin{abstract}
The needs of environmental protection led to the introduction of composites based on the use of plastics reinforced with biodegradable materials or other easily accessible materials. The overall purpose of the research was to experimentally investigate the possibilities of using some accessible reinforcement materials. Textile based on plants fibers and glass fibers were used as reinforcement materials, while the matrix was a polymer type material. An empirical mathematical model was proposed to highlight the effect of the number of glass fiber reinforcements on the tensile strength. The determined mathematical empirical model and graphical representations highlight how the number of glass fiber reinforcements affects the modulus of elasticity of the composite materials.
\end{abstract}

Keywords: Composite materials, Resin, Textile material reinforcement, Tensile strength, Empirical mathematical model

\section{Introduction}

The composite materials include metallic or nonmetallic materials mass reinforced with elements that are able to offer improved properties to the part made of such material. A distinct interface could be observed between the distinct constituents on a macroscale. The components of the composite material maintain their identity at least of microscopic level, but as an assembly, the composite material is characterized by certain properties that are not met in the case of each component material [1-3].

Taking into consideration the material used as a matrix, one could classify the composite materials in composites with polymer matrix, with a metallic matrix, with ceramic matrix and composites "carboncarbon" [4].

The composite with polymer matrix uses termorigid or thermoplastic resins and they could be reinforced with fibers of glass, carbon, boron, Kevlar, metallic materials, ceramic monocrystals [5, 6], etc.

One of the application fields where the composite materials could be preferred is the field of equipment intended to use the so-called regenerable energy resources. An regenerable energy is the eolian energy. Essential components of the eolian equipment that are performed sometimes of composite material are the wind blades [7-9]. These wind blades must be made of materials characterized by a low weight, but also by high mechanical resistance.

In the last decades, due to the requests of environment protection, the problem of using composite materials with reinforcement of biodegradable materials or materials that are easily recycled or easily accessible was considered and such materials could be certain textile materials based on the use of plants or glass fibers.

Ample research concerning the investigation of the manufacturing techniques applied in the case of lightweight epoxy composites was developed by L. Boccarusso [10]. His research was focused on the use of reinforcement made of hemp and also on the improvement of the composite materials flame resistance.

\footnotetext{
$\overline{\text { *email: nagit@tcm.tuiasi.ro }}$
} 
Lomov and Verpoest considered that by the control of the textile structure, there is the possibility of optimal placing of the fiber and net-shape preforms could be thus produced [11]. They showed that certain mechanical properties of the textile composites are more convenient by the interlacing of the yarns in the reinforcements.

To obtain a better prediction of the reinforcement deformation in the textile composite, Wang took into consideration the analysis by means of two distinct modes of testing and modeling: longitudinal compression mode, and transverse extension mode, respectively [12]. He measured the parameters of the mesoscale models by mechanical experiments and verified the simulation models using a tomography methodology.

Hamidi et al. used silk as a natural reinforcement in the case of silk/epoxy composite laminates [13]. They considered that the application of an external pressure after the resin infusion led to an improvement of the silk/epoxy interface and thus to better behavior of the composite material to the mechanical efforts.

Boboc investigated the elastic properties of a laminate composite material reinforced with fabrics when the elastic properties of laminas are known [14]. Another research objective was the analysis of the mechanical properties of the laminas when they are affected by cyclical mechanical efforts. The researcher has justified the better behavior of the materials after the cyclical efforts by the intense microfracturing of the matrix as a consequence of applying such type of efforts.

In order to obtain additional information concerning the possible use of some common and easily accessible materials as reinforcement materials when including polymer type matrix, experimental testing was designed and performed; the results of this research are analyzed in the present paper.

\section{Materials and methods}

To investigate the possibilities of using a wind blade made of a polymer composite that could be performed of easily accessible materials, the decision was to use a polymer that could be obtained of two liquid components whose mixing could determine the solidification process in a short time. As reinforcing materials, one took into consideration using of woven materials including commercial silk, jute, and glass fibers (Figure 1).

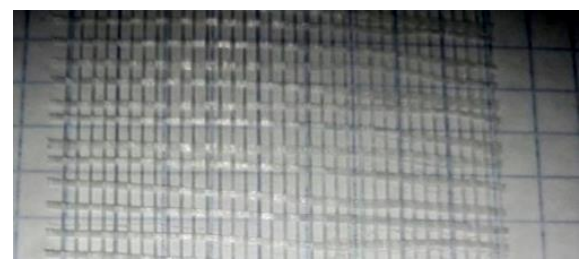

Figure 1. Aspect of the

glass fabric used as

reinforcing materials

Let us consider a composite material specimen as it is taken into consideration in the case of the tensile test. A generic cylindrical fiber surrounded by the matrix material could be considered. The assumption that in the considered case the fiber is placed along the specimen longitudinal axis was adopted (Figure 2, $b$ ).

Usually, the tensile strength of the reinforcing material is higher than the tensile strength of the matrix material. This means that the specimen could prove a tensile strength lower than the reinforcing material tensile strength, but higher than the matrix material tensile strength.

During the tensile test, due to the higher plasticity of the polymer matrix material, it is expected that for low values of the tensile effort, both the matrix material and reinforcement material will be affected by an elongation process. When the tensile effort becomes higher, there will be a moment when the matrix material will detach from the contact with the fiber type reinforcement material, while the fiber continues its elastic deformation. 

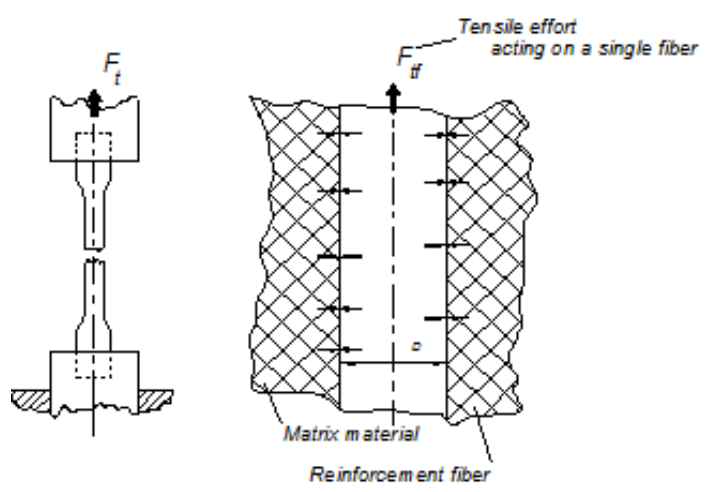

$b$

a
Figure 2. Behavior of the specimen $(a)$ and joining zone found between the reinforcement fiber material and the matrix material (b) during the tensile test

When the tensile effort generated in the reinforcement fiber becomes higher than the fiber tensile strength, the reinforcement fiber will break. Due to the breaking process, the strength of the joining zone between the reinforcement fiber material and matrix material could be exceeded and a separation between the two considered materials could develop. If the matrix material has high plasticity, even the braking process develops and affects the reinforcement fiber, the separation could not be produced in the matrix material. If the matrix material is not elastic enough, the breaking process could affect also this material and complete separation of the broken components initially included in the specimen could be observed. Due to the distinct behaviors of the two materials (matrix material and reinforcement fiber material), the breaking of the joining zone between the two material components could be noticed.

It is supposed that if the reinforcement fiber has a position inclined at a certain angle to the specimen longitudinal axis, the specimen tensile strength is diminished and lower forces will detach the matrix material from the complete contact with the reinforcement fiber material.

When the reinforcement material is a fabric, there are also fibers placed in a direction perpendicular or another position in respect with the specimen longitudinal axis, but it is presumed that these fibers could affect to a lesser extent the tensile strength of the composite specimen.

To prepare the specimens made of composite materials in less complex conditions, a mold was designed and achieved (figs. 3 and 4). The mold includes a main part made of silicone rubber. During the mold manufacturing process, the cavity from the mold was obtained using a model performed by classical cutting process applied to a plastic workpiece. A transparent glass cover allows observing the fulfilling of the mold cavity with the liquid polymer. The mixture of the two liquid materials needed to obtain each specimen was made and inserted into the mold using a syringe, after positioning the reinforcement inserts.

The dimensions of the model (in fact, the dimensions of the specimens obtained using the mold) were established in accordance with the recommendations included in some American regulations concerning the determination of the tensile characteristics of the composite of plastic reinforced with fibers. Such regulations are presented in [15]. The specimen total initial length was $L_{0}=200 \mathrm{~mm}$, the width in the specimen calibrated zone was $b_{0}=10 \pm 0.5 \mathrm{~mm}$ and the thickness in the same zone was $a_{0}=4 \pm 0.1 \mathrm{~mm}$.

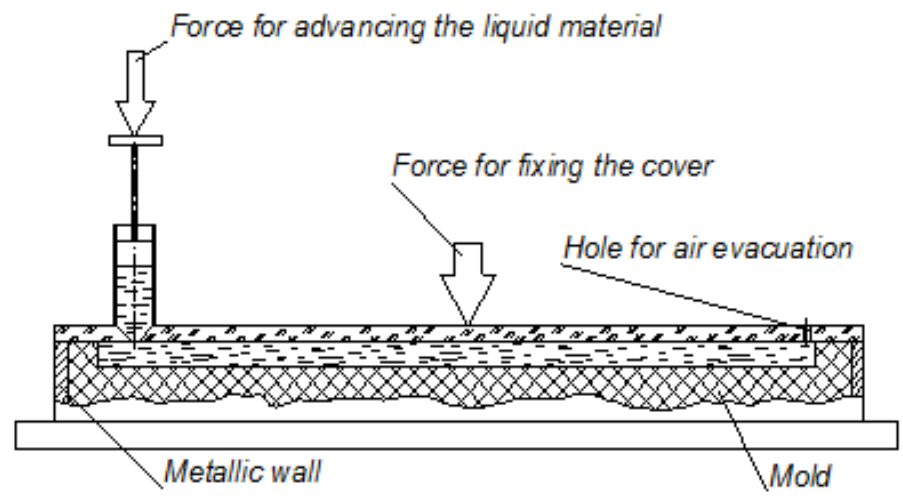

Figure 3. Schematical representation of the mold 
As matrix material for the composite specimens, a bicomponent polyurethane resin characterized by a short time of solidifying was used. The Sintafoam type resin (made by Prochima-Italy, tensile strength yield of about 13.0 - 65.0 MPa) was considered as a specimen material. The solidifying time after the mixing of the liquid components was less than $10 \mathrm{~min}$. The initial fluidity of the mix was high enough, thus being facilitated its penetration in narrow spaces. An important characteristic of this material was the low shrinkage in the solidifying process, allowing the performing of a specimen with the desired dimensions without the necessity of taking into consideration the shrinkage phenomenon.

Three commercial materials were used as composite reinforcements: silk fabric, jute fabric and glass fabric. Image of the glass fiber type material in the initial state is presented in figure 1.

Fibers with the diameters of $0.05 \mathrm{~mm}$ (silk insert), $0.6 \mathrm{~mm}$ (jute insert) and $0.185 \mathrm{~mm}$ (glass insert). The number of longitudinal fibers (that affect essentially the specimen tensile strength) for a single fabric insert was of 125 for silk, 4 for jute, and 8 for glass.

Certain difficulties were encountered during the specimens' preparation process. Thus, it has been observed that when pressing the liquid material with the aid of the syringe is not continuous, air bubbles could be introduced and such situations sometimes determined the need to repeat the manufacture of the specimens.

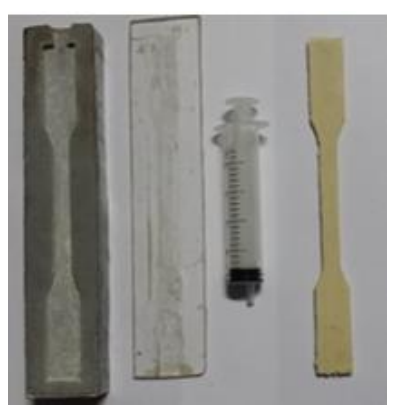

Figure 4. Image of the mold, mold cover, syringe for injection of liquid plastic material and of a specimen prepared inside

There were first performed distinct experiments on specimens that were containing a single reinforcement insert made of each of the tested materials (glass, jute, silk). By determining the tensile strength of the specimens, the conclusion that the highest tensile strength was corresponding to the glass insert was formulated. Forwards, other specimens that were including 2, 4, 6 and 7 glass inserts were prepared and tested, to identify how the number of reinforcements inserts exerts influence on the tensile strength of the composite material. An image concerning the used mold, mold transparent cover, syringe, and an obtained specimen is presented in figure 4.

\section{Results and discussions}

A set of specimens including jute, silk and glass fiber fabrics were prepared using the previously performed mold.

A computer-controlled electronic universal testing machine (WDW type, made in China) was used as a testing machine for the experimental research (Figure 5, a). The cross-head speed had a value of 1 $\mathrm{mm} / \mathrm{min}$. The clamping distance (length) between the grips for holding the specimen was of $100 \mathrm{~mm}$. The work zone of the universal testing machine during the performing of tensile strength testing of the considered composite materials could be seen in Figure 5, $b$.

Two images concerning the final results of the tensile tests could be observed in Figure 5, $c$ and $d$.

In figure 6 one could notice the deformation curves valid for some of the experimental cases developed when using distinct composite materials. These deformation curves were obtained by means of the software for operation of the computer-controlled universal testing machine. Taking into consideration the information offered by the graphical representations of the deformation curves, the maximum value of the stress was determined. Since the cross area of the specimen in its testing zone was of $4 \cdot 10=40 \mathrm{~mm}^{2}$, the value of the ultimate tensile strength was determined; there is the convention to consider the value that corresponds to the maximum stress in the specimen before breaking as the ultimate tensile strength or tensile strength. 
The value of the modulus of elasticity was calculated using the ratio of tensile stress to tensile strain.
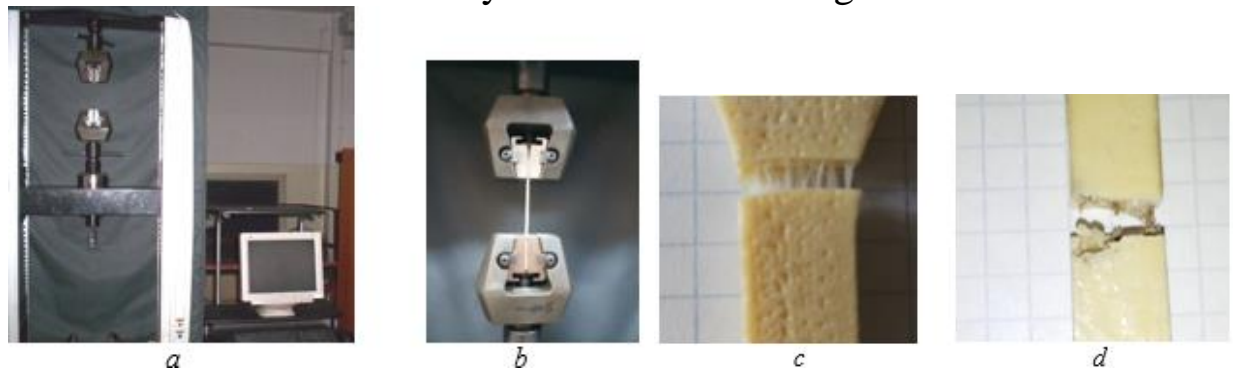

Figure 5. experimental conditions and results: $a$-wdw50 universal machine for mechanical tests; $b$ - work zone of the tensile test machine; $c$-specimen that included glass fiber reinforcement at the end of the test; $d-$ specimen that included jute fiber reinforcement at the end of test

The experimental results were firstly used to highlight the maximum tensile force valid for each of the prepared specimens and with this aim in view, the graphical representation from Figure 7 was elaborated. From Figure 7, it could be noticed that the lowest tensile force corresponds to the specimens for which the jute and the silk were used as reinforcement materials.

Adequate information concerning the elasticity properties of the considered reinforcement materials could be obtained by means of the modulus of elasticity and for that, based on the experimental results highlighted by the load-deformation curves, the values of the modulus of elasticity for each specimen were calculated.
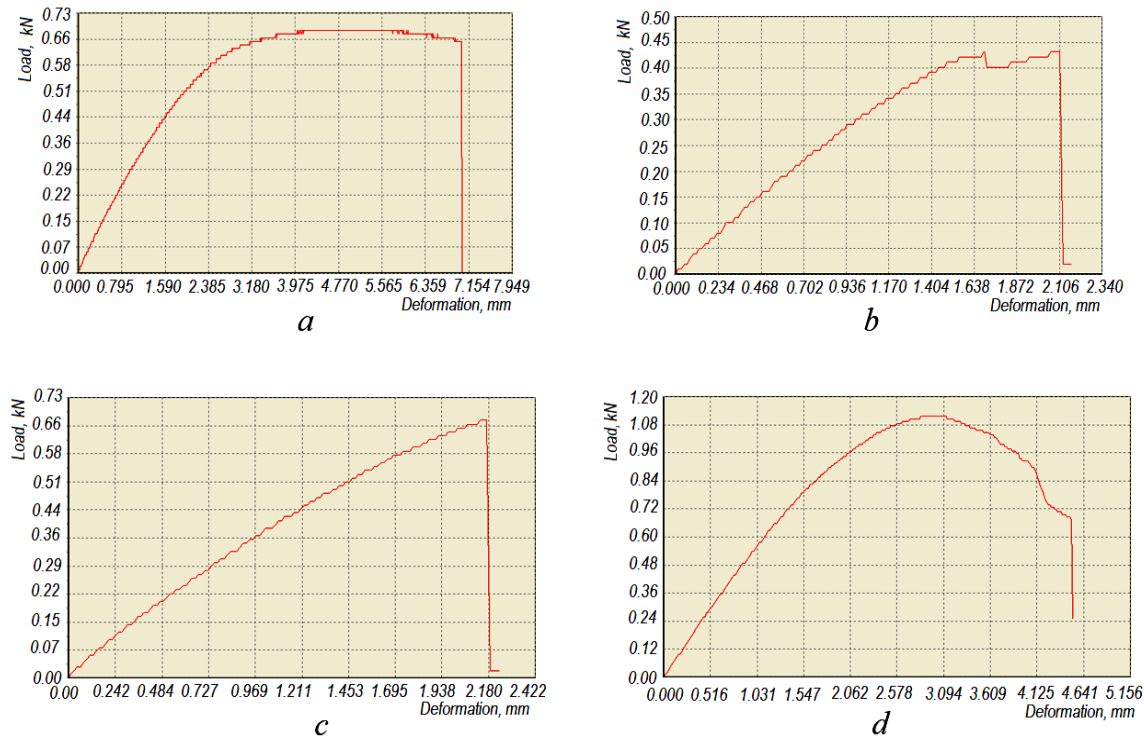

Figure 6. Load-deformation curves valid for some of the composite specimens: $a$ - when reinforcement components were not used; $b$-composite that includes a silk fabric; $c$-composite that includes a jute fabric; $d$-composite that includes four components of glass fiber fabric

Taking into consideration the calculated values of the elasticity modulus, the graphical representation from figure 8 was elaborated. Analyzing the information included in figure 8 , the relatively low values of the modulus of elasticity in the case of the jute and silk reinforcement materials could be observed. As it was expected, in the case of using the glass fiber fabric as reinforcement material, the value of elasticity modulus increases when the number of reinforcement components (the number of the glass fiber fabrics) increases, too. A certain contradiction appeared in the case of the specimen that does not contain reinforcement components whose peak load seems to be higher than the peak load of the specimens that contain one or two single glass inserts (Figure 7). To a certain extent, this contradiction could be explained by the presence of possible unobserved internal defects that were existing in the specimens containing one or two glass inserts. 


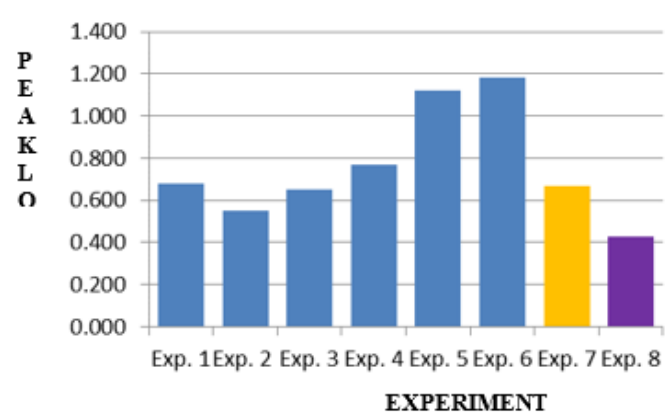

Figure 7. Peak load determined in the case of the tested composite materials (Exp. 1 - plastic specimen without reinforcement component, Exp. 2 - Exp.6, composite specimens containing 1, 2, 4, 6 and 7 fabrics of glass fiber reinforcement components; Exp. 7 - specimen that contains a single jute fiber reinforcement component (fabric); Exp. 8 - specimen that contains a single silk fiber reinforcement component (fabric)

As above-mentioned, the reinforcement based on the use of glass fibers proved a tensile strength higher than the tensile strength that corresponds to the other accessible fabric inserts made of natural materials (jute and silk). Considering this remark made after the first preliminary tests, other specimens were prepared using distinct numbers of reinforcement components that could be inserted into the mold. A single specimen was prepared for each number of glass fabric inserts. As expected, the increase in the number of glass fabric insert has determined an increase in the specimen's peak load. To quantify the intensity of the influence exerted by the number of the glass fabric type inserts on the modulus of elasticity $E_{g f}$ and to obtain additional information regarding this influence, the equation (1) was established by mathematical processing of the experimental results:

$E_{g f}=-53.85 x^{2}+7853.6 x+36615$,

where $x$ is the number of glass fiber components (fabrics) used as reinforcement inserts. The coefficient of determination has the value $R^{2}=0.9733$, this meaning that the number of reinforcement components (glass fabrics) exerts an influence evaluated at approximately $97.33 \%$ on the value of the modulus of elasticity $E_{g f}$.

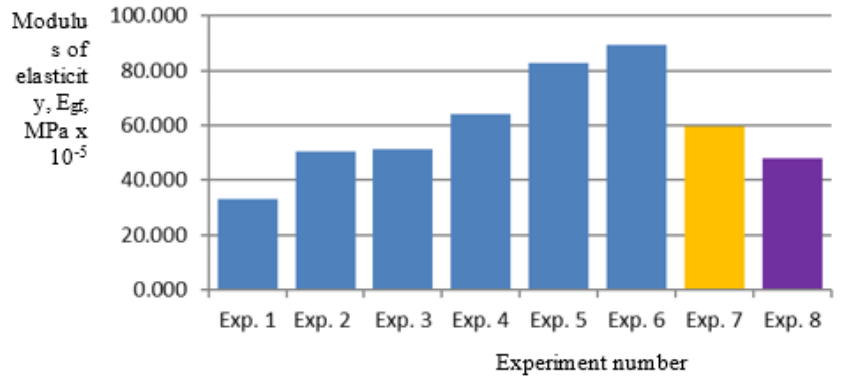

Figure 8. Values of the modulus of elasticity valid in the case of the tested composite materials (explanations for each experiment are the same as those mentioned in the case of figure 7)

\section{Conclusions}

Intending to identify the conditions of obtaining a wind blade made of easy-to-obtain composite material, experimental research involving the use of easily accessible composite materials and manufacturing tools was designed, aiming to test the tensile strength of such materials. A simple mold made of silicone base blend was designed and performed. Four types of specimens were achieved by means of the simple mold. As materials for the reinforcement components, the jute, silk and glass fiber fabrics were used. Since a high tensile strength was proved in the case of specimens made of glass fiber fabrics, extended experimental research was developed considering many such glass fiber reinforcement inserts. The initial analysis took into consideration the maximum tensile force for each of the prepared specimens. In the second research stage, the modulus of elasticity was considered as a criterion to evaluate the composite materials behavior at tensile tests. As expected, one noticed that a higher value 
of the modulus of elasticity could be obtained by increasing the number of glass fiber components. An empirical mathematical polynomial of second-degree type function was determined to highlight the intensity of the influence exerted by the number of the glass fiber components on the value of the modulus of elasticity. In the future, there is the intention to extend the experimental research by taking into consideration the use of other types of reinforcement materials included in the composite materials specimens and to improve the solution of the mold used for manufacturing the specimens.

Acknowlegments: This article was presented at Polymer Processing in Engineering Conference - PPE 2019, 7- 9 October 2019, Galati - Romania.

\section{References}

1.BALACHANDAR, M., VIJAYA RAMNATH, B., BARATH, R., BHARATH SANKAR, S., Mater Today-Proc, 16, 2019, p. 1006-1012.

2.DIXIT, S., GOEL, R., DUBEY, A., SHIVHARE, P.R., and BHALAVI, T., Polymers from Renewable Resources, 8, 2, 2017, p. 71-78.

3.MEDHANE, Y.U., International Journal of Engineering Research \& Technology (IJERT), 6, 8, 2017, p. 315-323.

4.WANG, R.-M., ZHENG, S.-R., ZHENG, Y.-P., Polymer matrix composites and technology, Science Press - Woodhead Publishing, 2011, available at https://www.elsevier.com/_ data/assets/ pdf_ file/0011/87176/Polymer-Matrix-Composites-and-Technology_ Intro_ Excerpt.pdf, accessed: 13.09.2019

5.MASUELLI, M.A., Introduction of Fibre-Reinforced Polymers - Polymers and Composites: Concepts, Properties and Processes. In Fiber Reinforced Polymers-The Technology Applied for Concrete Repair, Editor M.A. Masuelli, Intech, 2013

6.CHAWLA, K.K., Composite Materials. Science and Engineering. Springer, 2012.

7.CHEHOURI, A., Advances in composite wind turbine blades. A comparative study, Hamburg, Anchor Academic Publishing, 2014

8.NOLET, S., Composite Wind Blade Engineering and Manufacturing, 2011, available at http://web.mit.edu/windenergy/windweek/ Presentations/Nolet_Blades.pdf, accessed: 13.09.2019

9.CAIRNS, D.S., RIDDLE, T., NELSON, J., Wind turbine composite blade manufacturing: the need for understanding defect origins, prevalence, implications and reliability. Sandia Report SAND2011-1094, 2011, available at https://pdfs.semanticscholar.org/7b3a/ 1bca00347cca196a84c 2a66af109ec509745. pdf, accessed: 13.09.2019

10.BOCCARUSSO, L., On the manufacturing techniques of lightweight hemp-epoxy composites and improvement of their flame resistance. XXIX Phd Programme in Industrial Product and Process Engineering. Available at www.fedoa.unina.it/ 11767/1/Boccarusso_Luca_29.pdf, accessed: 08.05.2019.

11.LOMOV, S.V., VERPOEST, I., Textile Composite Materials: Polymer Matrix Composites, in Encyclopedia of Aerospace Engineering, 2010, John Wiley \& Sons, Ltd, available at: http://dl.iranmavad.com/sell/trans/ en/Polymer\%20Matrix\%20composites.pdf, accessed: 7.07.2019.

12.WANG, D., Mesoscopic modeling and simulation on the forming process of textile composites, Doctoral thesis (in French), Université de Lyon, 2016, p. 119.

13.HAMIDI, Y.K., YALCINKAYA, M.A., GULOGLU, G.E., PISHVAR, M., AMIRKHOSRAVI, M., AND M. CENGIZ ALTAN, M.C. Materials, 11, 2018, 2135.

14.BOBOC, A., Contributions to the study of the properties of composite materials reinforced with fabrics and of the cyclical solicitations effect on these properties. Doctoral thesis (in Romanian), "Dunărea de Jos" University of Galaţi, 2019.

15.***Composite materials tensile test (in Romanian), available at www.sim.utcluj.ro/stm/ download/ Mat_compozite/Inc_tractiune.pdf, accessed: 17.04.2019.

Manuscript received: 24.02 .2020 